\title{
Circulating natural antibodies to inflammatory cytokines are potential biomarkers for atherosclerosis
}

\author{
Peng Wang ${ }^{1}$, Huan Zhao', Zhenqi Wang ${ }^{2}$ and Xuan Zhang ${ }^{1 *}$
}

\begin{abstract}
Background: Inflammatory cytokines contribute to the development of atherosclerosis. Natural antibodies in the circulation have protective effects on common diseases including atherosclerosis-related conditions.

Purpose: The present study aimed to investigate the possible involvement of circulating IgG antibodies against inflammatory cytokines in atherosclerosis.

Methods: A total of 220 patients with diagnosis of atherosclerosis and 200 healthy controls were recruited. Seven linear peptide antigens were used to develop an enzyme-linked immunosorbent assay in-house for detection of plasma IgG antibodies against interleukin $1 \beta$ (fragments IL $1 \beta-1$ and IL1 $\beta-2$ ), IL6, IL8, tumor necrosis factor alpha (fragments TNFa-1 and TNFa-2) and IL1a.

Results: Atherosclerotic patients had an increase in the levels of circulating IgG to TNFa-1(adjusted $r^{2}=0.038$, $p<0.001$ ) and IL1a (adjusted $r^{2}=0.025, p=0.002$ ) compared with control subjects. Female patients mainly contributed to increased anti-TNFa-1 IgG levels (adjusted $r^{2}=0.073, p<0.001$ ) and anti-IL1a IgG levels (adjusted $r^{2}=0.044, p=0.003$ ). In addition, female patients showed higher anti-IL1 $\beta-2$ lgG levels than controls (adjusted $\left.r^{2}=0.023, p=0.026\right)$. There was no significant change of circulating IgG antibodies to other cytokines. ROC curve analysis showed an AUC of 0.564 for anti-TNFa- $1 \mathrm{lgG}$ assay with $22.8 \%$ sensitivity against a specificity of $90.0 \%$, and an AUC of 0.539 for anti-IL 1 a IgG assay with $17.8 \%$ sensitivity against a specificity of $90.0 \%$; the anti-IL1 $\beta-2$ lgG assay had an AUC of 0.580 with $26.3 \%$ sensitivity against a specificity of $89.8 \%$ in female patients. There was no correlation between plasma IgG levels and carotid intima-media thickness.
\end{abstract}

Conclusion: Natural antibodies to inflammatory cytokines may be potential biomarkers for atherosclerosis.

Keywords: Atherosclerosis, Natural antibodies, Inflammatory cytokines, ELISA

\section{Introduction}

Atherosclerosis, the most common cause of cardiovascular diseases, is a chronic and systemic inflammatory disorder mainly affecting the intima of large and medium-sized arteries [1]. Several risk factors are likely to be responsible for the development of atherosclerosis, such as smoking, diabetes mellitus, abdominal obesity, atherogenic dyslipidemia and hypertension [2,3]. Typically, it has long disease latency and frequently coexists in $>1$ vascular bed [4]. This disease can lead to myocardial and cerebral infarctions,

\footnotetext{
* Correspondence: zhangxuankj@163.com

1 Jilin Provincial Key Laboratory on Molecular and Chemical Genetics, Second Hospital of Jilin University, 218 Ziqiang Street, Changchun 130041, China Full list of author information is available at the end of the article
}

stroke as well as coronary heart disease $[4,5]$. Nowadays, cardiovascular disease accounts for approximately $30 \%$ of all health-related deaths worldwide, making atherosclerotic lesions a common cause of death [6]. Early diagnosis and treatment can slow or halt the worsening of atherosclerosis. It is thus imperative to develop effective methods for the detection of atherosclerosis at an early stage.

Natural autoantibodies in the circulation are emerging as promising diagnostic biomarkers for malignant diseases $[7,8]$. Recently, an increase in circulating levels of certain immunoglobulin G (IgG) has been identified in patients with atherosclerosis-related diseases. For instance, Machida et al. reported that circulating levels of auto-antibodies against replication protein A2 (RPA2)

(c) The Author(s). 2018 Open Access This article is distributed under the terms of the Creative Commons Attribution 4.0 International License (http://creativecommons.org/licenses/by/4.0/), which permits unrestricted use, distribution, and 
were found to be increased in patients with stroke [9]. Elevated levels of antibodies against coatomer protein complex subunit epsilon (COPE) and DAN family BMP antagonist (NBL1) have been suggested to contribute to a high risk of cardiovascular events in patients with obstructive sleep apnea [10, 11]. Therefore, the identification of natural autoantibodies may provide a promising approach for early detection of atherosclerosis-related diseases.

Inflammatory cytokines, including tumor necrosis factor alpha (TNF- $\alpha$ ), interleukin (IL) $1 \alpha$ (IL1 $\alpha)$, IL1ß, IL-2, IL6 and IL8 are involved in the pathogenesis of atherosclerosis, participating in all stages of this condition $[12,13]$. In this study, our main goal was to examine the association between circulating antibody levels against inflammatory cytokines and atherosclerosis, which may identify effective biomarkers for the diagnosis of atherosclerosis.

\section{Materials and methods Subjects}

A total of 220 patients diagnosed with atherosclerosis and 200 healthy controls were enrolled from the Second Hospital of Jilin University for this study. Their demographic characteristics are given in Table 1. The inclusion criteria was the presence of abnormal carotid intima-media thickness (CIMT), which is a useful measure for subclinical atherosclerosis and directly associated with an increased risk of both myocardial infarction and ischemic stroke, was measured by vascular ultrasound. Control samples were collected from local communities in the same period as the collection of case samples. Those subjects who had thyroid diseases or other autoimmune diseases such as type-1 diabetes and inflammatory bowel diseases, and those with any type of malignant tumors, were not included for this study. All subjects were of Han Chinese origin

Table 1 Demographic and clinical characteristics of patients and control subjects

\begin{tabular}{lllll}
\hline Characteristics & $\begin{array}{l}\text { Patients } \\
(n=220)\end{array}$ & $\begin{array}{l}\text { Controls } \\
(n=200)\end{array}$ & $\mathrm{t} / \mathrm{X}^{2}$ & $P$ value \\
\hline Gender, $\mathrm{n}(\%)$ & & & 0.016 & 0.898 \\
$\quad$ Male & $124(56.6)$ & $112(56.0)$ & & \\
Female & $96(43.4)$ & $88(44.0)$ & & \\
Age (years) & $61.1 \pm 11.4$ & $60.8 \pm 11.8$ & 0.234 & 0.815 \\
Site of plaques & & & & \\
Carotid artery & $6(2.7)$ & - & & \\
Carotid bifurcation & $52(23.7)$ & - & & \\
Internal carotid artery & $39(17.8)$ & - & & \\
Internal carotid bifurcation & $2(0.9)$ & - & & \\
Common carotid artery & $100(45.7)$ & - & & \\
$\quad$ Subclavian artery & $20(9.1)$ & - & & \\
\hline
\end{tabular}

and all provided written informed consent to participant in this study. This work was approved by the Ethics Committee of Jilin University Second Hospital and conformed to the Declaration of Helsinki.

\section{Antibody testing}

Seven linear peptide antigens derived from IL1 $\alpha$, IL1 $\beta$, IL6, IL8 and TNF $\alpha$ were designed based on computational epitope prediction tools (www.iedb.org) and then synthesized by solid-phase chemical method with a purity of $>95 \%$. The detail of each antigen designed is listed in Table 2. An enzyme-linked immunosorbent assay (ELISA) was developed in-house with these 7 peptide antigens based on previous studies [14]. Briefly, each synthetic peptide antigens was dissolved in $67 \%$ acetic acid as a stock solution of $5 \mathrm{mg} / \mathrm{ml}$; a working solution of $20 \mu \mathrm{g} / \mathrm{ml}$ in coating buffer $(0.1 \mathrm{~m}$ phosphate buffer containing $10 \mathrm{~mm}$ EDTA and $0.15 \mathrm{~m} \mathrm{NaCl}, \mathrm{pH} 7.2$ ) was used to coat maleimide-activated 96 well microtiter plates (Cat. 15,150, Thermo Scientific, Rockford, IL, USA) based on the manufacturer's instructions and stored at $4{ }^{\circ} \mathrm{C}$ until use. After the antigen-coated microplate was washed twice with $200 \mu \mathrm{l}$ phosphate-buffered saline (PBS) containing 0.1\% Tween-20, $50 \mu \mathrm{l}$ Assay Buffer (PBS containing 0.5\% bovine serum albumin (BSA)) was added to each negative control (NC) well and $50 \mu \mathrm{l}$ of the diluted plasma and positive control (PC) sample (1100 dilution) in Assay Buffer to the sample wells. After incubation for $1.5 \mathrm{~h}$ at room temperature, the plate was washed 3 times with $200 \mu \mathrm{l}$ Wash Buffer and $50 \mu \mathrm{l}$ goat anti-human IgG antibody conjugated to peroxidase (ab98567, Abcam, Beijing, China) (1,50,000 dilution in Assay Buffer) was then added. The plate was incubated at room temperature for $1 \mathrm{~h}$, and $50 \mu \mathrm{l}$ Stabilized Chromogen (SB02, Life Technologies, Guangzhou, China) was used for color development. A microplate reader (BioTek, Winooski, VT, USA) was used to measure the optical density (OD) at $450 \mathrm{~nm}$ and a reference wavelength of $620 \mathrm{~nm}$.

All the samples were assayed in duplicate and relative levels of plasma IgG antibodies were expressed as the

Table 2 Sequence of peptide antigens used for the in-house ELISA

\begin{tabular}{lll}
\hline Antigens & Sequence $(\mathrm{N} \rightarrow \mathrm{C})$ & NCBI accession \\
\hline IL1a & H-WETHGTKNYFTSVAHPNLFIATKQDYWVC-OH & NP_000566 \\
IL1ß-1 & H-SLNCTLRDSQQKSLVMSGPYELKALHLQG-OH & NP_000567 \\
IL13-2 & H-KHAYYSGNEDDLFFEADGPKQMKCH-OH & NP_000567 \\
IL6 & H-LTKLQAQNQWLQDMTTHLILRSC-OH & NP_000591 \\
IL8 & H-DCQCIKTYSKPFHPKFIKELRVIESD-OH & NP_000575 \\
TNFa-1 & H-CQLQWLNRRANALLANGVELRDNQLV-OH & NP_000585 \\
TNFa-2 & H-KSAIKSPCQRETPEGAEAKPWYEPK-OH & NP_000585 \\
\hline
\end{tabular}


Table 3 Inter-assay deviation between ELISA-testing plates

\begin{tabular}{llll}
\hline Factors & Number of plates & Mean \pm SD & CV (\%) \\
\hline IL1 $\beta-1$ & 20 & $0.67 \pm 0.11$ & $16.94 \%$ \\
IL6 & 20 & $1.21 \pm 0.15$ & $12.11 \%$ \\
IL8 & 20 & $1.28 \pm 0.12$ & $9.42 \%$ \\
TNFa-1 & 20 & $1.24 \pm 0.07$ & $5.87 \%$ \\
IL1a & 20 & $0.93 \pm 0.07$ & $7.45 \%$ \\
IL1 $\beta-2$ & 20 & $1.14 \pm 0.10$ & $9.12 \%$ \\
TNFa-2 & 20 & $1.79 \pm 0.29$ & $16.10 \%$ \\
\hline SD stand
\end{tabular}

$S D$ standard deviation, $C V$ coefficient of variation specific binding ratio (SBR) that was calculated as follows:

$$
\mathrm{SBR}=\left(\mathrm{OD}_{\text {Sample }}-\mathrm{OD}_{\mathrm{NC}}\right) /\left(\mathrm{OD}_{\mathrm{PC}}-\mathrm{OD}_{\mathrm{NC}}\right) .
$$

\section{Data analysis}

An inter-assay deviation was estimated by the coefficient of variation $(\mathrm{CV})$ calculated based on the measurement of a pooled plasma sample randomly collected from $>20$ healthy subjects, namely quality control (QC) sample that was tested on every plate. Plasma IgG levels were expressed as the mean \pm standard deviation (SD) in SBR, and Student's $t$-test was used to examine the differences between the patient group and the control group. Linear regression analysis was applied to test the effects of disease status on the IgG levels with adjustment for age and

Table 4 Differences of circulating lgG between the two groups

\begin{tabular}{|c|c|c|c|c|}
\hline Factors & Atherosclerosis (Mean \pm SD) & Control (Mean \pm SD) & $t$ & $P$ value \\
\hline \multicolumn{5}{|l|}{ IL1 $\beta-1$} \\
\hline Male & $0.651 \pm 0.310$ & $0.657 \pm 0.358(112)$ & -0.138 & 0.890 \\
\hline Female & $0.674 \pm 0.331(96)$ & $0.634 \pm 0.419(88)$ & 0.709 & 0.480 \\
\hline Total & $0.661 \pm 0.319(220)$ & $0.647 \pm 0.385(200)$ & 0.399 & 0.690 \\
\hline \multicolumn{5}{|l|}{ IL6 } \\
\hline Male & $1.204 \pm 0.357(124)$ & $1.188 \pm 0.350(112)$ & 0.353 & 0.725 \\
\hline Female & $1.297 \pm 0.437(96)$ & $1.199 \pm 0.545(88)$ & 1.349 & 0.179 \\
\hline Total & $1.244 \pm 0.396(220)$ & $1.193 \pm 0.445(200)$ & 1.259 & 0.209 \\
\hline \multicolumn{5}{|l|}{ IL8 } \\
\hline Male & $1.087 \pm 0.300(124)$ & $1.092 \pm 0.295(112)$ & -0.105 & 0.916 \\
\hline Female & $1.145 \pm 0.292(96)$ & $1.101 \pm 0.307$ (88) & 1.007 & 0.315 \\
\hline Total & $1.113 \pm 0.298(220)$ & $1.096 \pm 0.300(200)$ & 0.581 & 0.561 \\
\hline \multicolumn{5}{|l|}{ TNFa-1 } \\
\hline Male & $1.198 \pm 0.296(124)$ & $1.145 \pm 0.265(112)$ & 1.438 & 0.152 \\
\hline Female & $1.291 \pm 0.302(96)$ & $1.133 \pm 0.253(88)$ & 3.810 & $<0.001$ \\
\hline Total & $1.238 \pm 0.301(220)$ & $1.140 \pm 0.259(200)$ & 3.588 & $<0.001$ \\
\hline \multicolumn{5}{|l|}{ IL1a } \\
\hline Male & $0.883 \pm 0.162(124)$ & $0.852 \pm 0.159(112)$ & 1.490 & 0.138 \\
\hline Female & $0.906 \pm 0.148(96)$ & $0.835 \pm 0.176(88)$ & 2.964 & 0.003 \\
\hline Total & $0.893 \pm 0.156(220)$ & $0.845 \pm 0.166(200)$ & 3.084 & 0.002 \\
\hline \multicolumn{5}{|l|}{ IL $1 \beta-2$} \\
\hline Male & $1.008 \pm 0.201(124)$ & $1.008 \pm 0.233(112)$ & 0.031 & 0.975 \\
\hline Female & $1.085 \pm 0.270(96)$ & $1.002 \pm 0.224(88)$ & 2.248 & 0.026 \\
\hline Total & $1.042 \pm 0.236(220)$ & $1.005 \pm 0.229(200)$ & 1.603 & 0.110 \\
\hline \multicolumn{5}{|l|}{ TNFa-2 } \\
\hline Male & $1.385 \pm 0.427(124)$ & $1.457 \pm 0.497(112)$ & -1.195 & 0.233 \\
\hline Female & $1.486 \pm 0.426(96)$ & $1.492 \pm 0.431$ & -0.090 & 0.928 \\
\hline Total & $1.429 \pm 0.428(220)$ & $1.472 \pm 0.468(200)$ & -0.991 & 0.322 \\
\hline
\end{tabular}


gender. Receiver operating characteristic (ROC) curve analysis was performed to assess the value of plasma IgG indicators for the diagnosis of atherosclerosis, with calculation of an area of the ROC curve (AUC) and 95\% confidence interval $(\mathrm{CI})$ as well as a sensitivity against the specificity of $>90 \%$. The $p$-value of $<0.05$ was considered to be statistically significant. All statistical tests were performed with SPSS 19.0 software (IBM, Armonk, New York).

\section{Results}

All CV calculated with SBR of the QC sample was less than $20 \%$ (Table 3 ), suggesting a good reproducibility for the in-house ELISA. As shown in Table 4, plasma anti-TNF $\alpha-1$ IgG levels were significantly higher in patients with atherosclerosis patients than control subjects $(t=3.588, p<0.001)$, female patients mainly contributing to increased anti-TNF $\alpha$-1IgG levels in atherosclerosis $(t=3.810, p<0.001)$. In addition, patients with atherosclerosis had a significantly higher level of circulating IgG against IL1 $\alpha$ antigens than control subjects $(t=$ 3.084, $p=0.002$ ) and female patients mainly contributed to the significant change $(t=2.964, p=0.003)$. While anti-IL1 $\beta$-2 IgG level was significantly higher than in female patients than female controls $(p=0.026)$, there was no significant difference was found in combined groups.

As shown in Table 5, linear regression analysis showed that atherosclerotic patients had an increase in circulating anti-TNF $\alpha-1$ IgG levels (adjusted $r^{2}=0.038, p<0.001$ ) and anti-IL1 $\alpha$ IgG level (adjusted $r^{2}=0.025, p=0.002$ ) compared with control subjects, female patients mainly contributing to increased anti-TNF $\alpha-1$ IgG levels (adjusted $\left.r^{2}=0.073, p<0.001\right)$ and increased anti-IL1 $\alpha$ IgG levels (adjusted $r^{2}=0.044, p=0.003$ ). Additionally, female patients had an increase in anti-IL1 $\beta-2$ IgG levels compared to female controls (adjusted $r^{2}=0.023, p=0.026$ ).

ROC curve analysis revealed an AUC of 0.564 (95\% CI0.509-0.619) for anti-TNF $\alpha-1$ IgG assay with $22.8 \%$ sensitivity against the specificity of $90.0 \%$, and an AUC of 0.539 (95\% CI 0.484-0.594) for anti-IL1 $\alpha$ IgG assay with $17.8 \%$ sensitivity against the specificity of $90.0 \%$. Moreover, ROC curve analysis performed only in females showed that anti-TNFo-1 IgG assay had an AUC of 0.591 (95\% CI $0.509-0.673$ ) with $28.4 \%$ sensitivity against a specificity of $89.8 \%$, and anti-IL $1 \alpha$ IgG assay had an AUC of 0.549 (95\% CI $0.466-0.632)$ with $20.0 \%$ sensitivity against a specificity of $89.8 \%$, and anti-IL1 $1 \beta-2$ IgG assay had an AUC of 0.580 (95\% CI $0.498-0.663$ ) with $26.3 \%$ sensitivity against a specificity of $89.8 \%$ (Fig. 1).

As shown in Table 6, there was no correlation between plasma IgG levels and CIMT.

\section{Discussion}

Recent studies have demonstrated the presence of natural autoantibodies in blood of patients with atherosclerosis,
Table 5 Multivariate linear regression analysis of circulating lgG against cytokines in atherosclerosis

\begin{tabular}{|c|c|c|c|}
\hline Factors & Adjusted $R^{2}$ & $P$ value ${ }^{*}$ & $\beta \& 95 \% \mathrm{Cl}$ \\
\hline \multicolumn{4}{|l|}{ IL1 $\beta-1$} \\
\hline Male & -0.001 & 0.866 & $-0.007(-0.093,0.078)$ \\
\hline Female & -0.008 & 0.481 & $0.039(-0.071,0.150)$ \\
\hline Total & -0.004 & 0.698 & $0.013(-0.054,0.081)$ \\
\hline \multicolumn{4}{|l|}{ IL6 } \\
\hline Male & -0.006 & 0.736 & $0.016(-0.075,0.107)$ \\
\hline Female & 0.003 & 0.179 & $0.098(-0.045,0.242)$ \\
\hline Total & 0.001 & 0.204 & $0.052(-0.029,0.133)$ \\
\hline \multicolumn{4}{|l|}{ IL8 } \\
\hline Male & -0.009 & 0.915 & $-0.004(-0.081,0.073)$ \\
\hline Female & 0.003 & 0.316 & $0.045(-0.043,0.132)$ \\
\hline Total & -0.001 & 0.564 & $0.017(-0.041,0.074)$ \\
\hline \multicolumn{4}{|l|}{ TNFa-1 } \\
\hline Male & 0.012 & 0.161 & $0.051(-0.021,0.124)$ \\
\hline Female & 0.073 & $<0.001$ & $0.157(0.076,0.239)$ \\
\hline Total & 0.038 & $<0.001$ & $0.098(0.044,0.152)$ \\
\hline \multicolumn{4}{|l|}{ IL1a } \\
\hline Male & 0.012 & 0.146 & $0.030(-0.011,0.071)$ \\
\hline Female & 0.044 & 0.003 & $0.071(0.024,0.118)$ \\
\hline Total & 0.025 & 0.002 & $0.048(0.017,0.079)$ \\
\hline \multicolumn{4}{|l|}{ IL $1 \beta-2$} \\
\hline Male & 0.009 & 0.988 & $-0.0004(-0.056,0.055)$ \\
\hline Female & 0.023 & 0.026 & $0.083(0.010,0.155)$ \\
\hline Total & 0.017 & 0.111 & $0.036(-0.008,0.080)$ \\
\hline \multicolumn{4}{|l|}{ TNFa-2 } \\
\hline Male & 0.012 & 0.215 & $-0.074(-0.192,0.044)$ \\
\hline Female & -0.011 & 0.928 & $-0.006(-0.131,0.120)$ \\
\hline Total & 0.006 & 0.316 & $-0.044(-0.130,0.042)$ \\
\hline
\end{tabular}

*Adjusted $P$-value for age in male and female samples, and for gender and age in combined samples; $\mathrm{Cl}$ confidence interval

such as anti-apolipoprotein A-1 antibodies and anti-lipoprotein lipase antibodies $[15,16]$. TNF $\alpha$ induces a pro-inflammatory process in endothelial cells, altering function of endothelial and vascular smooth muscle cells, which is crucially involved in the progression of atherosclerosis and heart failure $[17,18]$. A study suggests that the role of IL- $1 \alpha$ in atherogenesis should be targeted in patients with cardiovascular disease [19]. Decreased IL1 $\beta$ level was found to be related to the inhibition of platelet aggregation and thromboembolic-related disorders [20]. In this study, we found that plasma anti-TNF $\alpha$ and anti-IL1 $\alpha$ IgG levels were significantly increased in patients with atherosclerosis compared with control subjects, and an increase in anti-IL1 $\beta$ IgG level was found in female patients (Table 4). Although circulating levels of anti-TNF $\alpha$ and anti-IL1 $\alpha$ IgG 

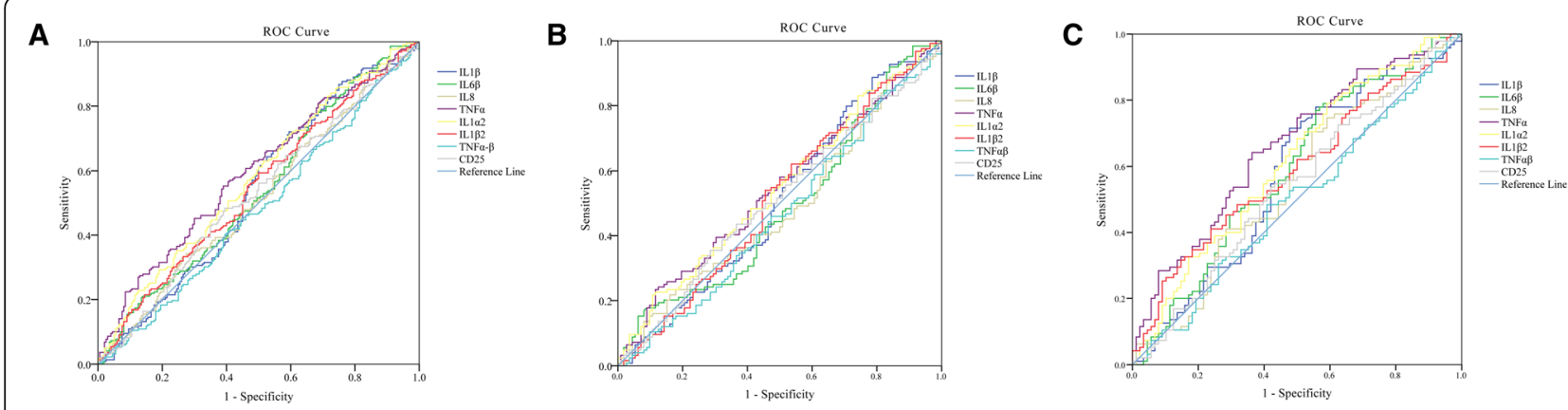

Fig. 1 ROC curve analysis of circulating lgG in atherosclerosis. a combined subjects; (b) male subjects; (c) female subjects

antibodies were significantly increased in atherosclerosis, ROC curve analysis revealed relatively low sensitivity (Fig. 1). Possibly, such an antibody test cannot serve as highly effective biomarkers for diagnosis of the disease but represent a subgroup of atherosclerotic patients who may have developed chronic inflammation in their body. Nevertheless, the findings suggest that natural antibodies against inflammatory cytokines such as TNF $\alpha$, IL1 $\alpha$, and IL $1 \beta$ may serve as useful biomarkers for the identification of atherosclerotic subgroup that may need immunological treatment although whether the levels of these inflammatory cytokines are correlated with their antibody levels in the circulation need further investigation.

Several studies have indicated gender differences in the development of atherosclerosis [21, 22]. Androgens could up-regulate the expression of atherosclerosis-related genes in macrophages from males but not females, suggesting genetic predisposition to atherosclerosis only in male subjects [23]. Knowledge into biological differences in atherosclerosis between men and women remains incomplete. In this study, the gender differences in circulating IgG antibodies to inflammatory cytokines were observed, so that up-regulation of anti-TNF $\alpha$, anti-IL1 $\alpha$, and anti-IL1 $\beta$ IgG levels were more likely to occur in female than male patients with atherosclerosis. Collectively, the gender differences in circulating IgG antibodies to inflammatory cytokines may provide a clue to insights into the pathophysiology of atherosclerosis.

Table 6 The correlations between plasma IgG levels and CIMT

\begin{tabular}{llll}
\hline Factors & df & Coefficients of correlation & $P$ value \\
\hline IL1 $\beta-1$ & 218 & 0.053 & 0.432 \\
IL6 & 218 & 0.007 & 0.920 \\
IL8 & 218 & 0.060 & 0.379 \\
TNFa-1 & 218 & 0.003 & 0.968 \\
IL1a & 218 & 0.058 & 0.397 \\
IL1 $\beta-2$ & 218 & -0.081 & 0.234 \\
TNFa-2 & 218 & -0.064 & 0.347 \\
\hline
\end{tabular}

Technically, ELISA antibody tests with individual antigens may have a relatively low sensitivity as shown in this study. Possibly, such an antibody test alone is unlikely to screen people with atherosclerosis in clinical practice. Several studies have demonstrated that a panel of cancer-associated antigens had a high sensitivity for early detection of cancer $[24,25]$. Future work on identification of a panel of such linear peptide antigens may provide an aid to early screening of atherosclerosis.

\section{Conclusions}

Natural antibodies to inflammatory cytokines may be potential biomarkers for atherosclerosis although further replication with a large sample size is needed to confirm this initial finding.

\section{Abbreviations}

AUC: Areas under the ROC curve; BSA: Bovine serum albumin; Cl: Confident interval; CIMT: Carotid intima-media thickness; CV: Coefficients of Variation; ELISA: Enzyme-linked immunosorbent assay; IgG: Immunoglobulin G; IL1a: Interleukin 1a; IL 1 $\beta-1$ : Interleukin $1 \beta$ derived antigen 1; IL1 $\beta$ 2: Interleukin $1 \beta$ derived antigen 2; IL6: Interleukin 16; IL8: Interleukin 8; NC: Negative control; OD: Optical density; PBS: Phosphate -buffered saline; PC: Positive control; QC: Quality control; ROC: Receiver operating characteristic curve; RPA2: Replication protein A2; SBR: Specific binding ratio; TNFa-1: Tumor Necrosis Factor a derived antigen 1; TNFa-2: Tumor Necrosis Factor a derived antigen 2; WHO: World Health Organization

\section{Acknowledgements}

We thank all the patients and control subjects for their participation in this study. This work was supported by Hailanshen Biomedical \&Technology Ltd., Shenzhen, China.

\section{Funding}

This work was supported by Hailanshen Biomedical Technology Ltd., Shenzhen, China.

\section{Authors' contributions}

Wang P mainly carried out laboratory work and data analysis; Zhao $\mathrm{H}$ and Wang $\mathrm{Z}$ identified patients with atherosclerosis and collected clinical data; Zhang $X$ conceived of this study, supervised laboratory work and drafted manuscript. All authors read and approved the final manuscript.

\section{Ethics approval and consent to participate}

This work was approved by the Ethics Committees of the Second Hospital of Jilin University, Changchun, China, (IRB\#: SHJU2017-099), and performed in accordance with the 1964 Helsinki declaration and its later amendments or comparable ethical standards. 


\section{Consent for publication}

Not applicable.

\section{Competing interests}

All authors declared that they have no competing interests.

\section{Publisher's Note}

Springer Nature remains neutral with regard to jurisdictional claims in published maps and institutional affiliations.

\section{Author details}

'Jilin Provincial Key Laboratory on Molecular and Chemical Genetics, Second Hospital of Jilin University, 218 Ziqiang Street, Changchun 130041, China.

${ }^{2}$ School of Public Health, Jilin University, Changchun 130021, China.

Received: 27 July 2018 Accepted: 5 November 2018

Published online: 16 November 2018

\section{References}

1. Kao CW, Wu PT, Liao MY, Chung IJ, Yang KC, Tseng WI, et al. Magnetic nanoparticles conjugated with peptides derived from monocyte chemoattractant Protein-1 as a tool for targeting atherosclerosis. Pharmaceutics. 2018;10(2):62.

2. Knopp RH, Paramsothy P. Treatment of hypercholesterolemia in patients with metabolic syndrome: how do different statins compare? Nat Clin Pract Endocrinol Metab. 2006:2:136-7.

3. Lantos I, Endresz V, Virok DP, Szabo A, Lu X, Mosolygo T, et al. Chlamydia pneumoniae infection exacerbates atherosclerosis in ApoB100only/LDLR(-/-) mouse strain. Biomed Res Int. 2018;2018:8325915.

4. Herrington W, Lacey B, Sherliker P, Armitage J, Lewington S. Epidemiology of atherosclerosis and the potential to reduce the global burden of Atherothrombotic disease. Circ Res. 2016;118:535-46.

5. Berlin-Broner Y, Febbraio M, Levin L. Apical periodontitis and atherosclerosis: is there a link? Review of the literature and potential mechanism of linkage. Quintessence Int. 2017:48:527-34.

6. Bhatnagar P, Wickramasinghe K, Williams J, Rayner M, Townsend N. The epidemiology of cardiovascular disease in the UK 2014. Heart. 2015;101:1182-9.

7. Chen C, Huang Y, Zhang C, Liu T, Zheng HE, Wan S, et al. Circulating antibodies to p16 protein-derived peptides in breast cancer. Mol Clin Oncol. 2015;3:591-4

8. Zhao H, Zhang $X$, Han Z, Wang Z, Wang Y. Plasma anti-BIRC5 IgG may be a useful marker for evaluating the prognosis of nonsmall cell lung cancer. FEBS Open Bio. 2018;8:829-35.

9. Machida T, Kubota M, Kobayashi E, Iwadate $Y$, Saeki N, Yamaura A, et al. Identification of stroke-associated-antigens via screening of recombinant proteins from the human expression cDNA library (SEREX). J Transl Med. 2015;13:015-0393.

10. Matsumura T, Terada J, Kinoshita T, Sakurai Y, Yahaba M, Tsushima K, et al. Circulating autoantibodies against neuroblastoma suppressor of tumorigenicity 1 (NBL1): a potential biomarker for coronary artery disease in patients with obstructive sleep apnea. PLoS One. 2018;13(3):e0195015.

11. Matsumura T, Terada J, Kinoshita T, Sakurai Y, Yahaba M, Ema R, et al. Circulating anti-Coatomer protein complex subunit epsilon (COPE) autoantibodies as a potential biomarker for cardiovascular and cerebrovascular events in patients with obstructive sleep apnea. J Clin Sleep Med. 2017;13:393-400

12. Ramji DP, Davies TS. Cytokines in atherosclerosis: key players in all stages of disease and promising therapeutic targets. Cytokine Growth Factor Rev. 2015;26:673-85.

13. Tousoulis D, Oikonomou E, Economou EK, Crea F, Kaski JC. Inflammatory cytokines in atherosclerosis: current therapeutic approaches. Eur Heart J. 2016:37:1723-32

14. Hallford P, St Clair D, Halley L, Mustard C, Wei J. a study of type-1 diabetes associated autoantibodies in schizophrenia. Schizophr Res. 2016:176:186-90.

15. Montecucco F, Vuilleumier N, Pagano S, Lenglet S, Bertolotto M,

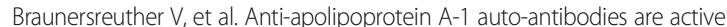
mediators of atherosclerotic plaque vulnerability. Eur Heart J. 2011;32:412-21.

16. Fesmire J, Wolfson-Reichlin M, Reichlin M. Effects of autoimmune antibodies anti-lipoprotein lipase, anti-low density lipoprotein, and anti-oxidized low density lipoprotein on lipid metabolism and atherosclerosis in systemic lupus erythematosus. Rev Bras Reumatol. 2010;50:539-51.
17. Hot A, Lenief V, Miossec P. Combination of IL-17 and TNFalpha induces a pro-inflammatory, pro-coagulant and pro-thrombotic phenotype in human endothelial cells. Ann Rheum Dis. 2012;71:768-76.

18. Kleinbongard P, Heusch G, Schulz R. TNFalpha in atherosclerosis, myocardial ischemia/reperfusion and heart failure. Pharmacol Ther. 2010;127:295-314.

19. Freigang $S$, Ampenberger $F$, Weiss A, Kanneganti TD, Iwakura $Y$, Hersberger $M$, et al. Fatty acid-induced mitochondrial uncoupling elicits inflammasomeindependent IL-1alpha and sterile vascular inflammation in atherosclerosis. Nat Immunol. 2013:14:1045-53.

20. Alarcon M, Fuentes E, Olate N, Navarrete S, Carrasco G, Palomo I. Strawberry extract presents antiplatelet activity by inhibition of inflammatory mediator of atherosclerosis (sP-selectin, SCD40L, RANTES, and IL-1beta) and thrombus formation. Platelets. 2015;26:224-9.

21. Bairey Merz CN, Shaw L, Reis SE, Bittner V, Kelsey SF, Olson M, et al. Insights from the NHLBl-sponsored Women's ischemia syndrome evaluation (WISE) study: part Il: gender differences in presentation, diagnosis, and outcome with regard to gender-based pathophysiology of atherosclerosis and macrovascular and microvascular coronary disease. J Am Coll Cardiol. 2006;47:084.

22. Mendelsohn ME, Karas RH. Molecular and cellular basis of cardiovascular gender differences. Science. 2005;308:1583-7.

23. Ng MK, Quinn CM, McCrohon JA, Nakhla S, Jessup W, Handelsman DJ, et al. Androgens up-regulate atherosclerosis-related genes in macrophages from males but not females: molecular insights into gender differences in atherosclerosis. J Am Coll Cardiol. 2003:42:1306-13.

24. Lam S, Boyle P, Healey GF, Maddison P, Peek L, Murray A, et al. EarlyCDTlung: an immunobiomarker test as an aid to early detection of lung cancer. Cancer Prev Res (Philadelphia, Pa). 2011:4:1126-34

25. Chapman CJ, Healey GF, Murray A, Boyle P, Robertson C, Peek LJ, et al. EarlyCDT(R)-lung test: improved clinical utility through additional autoantibody assays. Tumour Biol. 2012;33:1319-26.

Ready to submit your research? Choose BMC and benefit from:

- fast, convenient online submission

- thorough peer review by experienced researchers in your field

- rapid publication on acceptance

- support for research data, including large and complex data types

- gold Open Access which fosters wider collaboration and increased citations

- maximum visibility for your research: over $100 \mathrm{M}$ website views per year

At BMC, research is always in progress.

Learn more biomedcentral.com/submissions 